\title{
ОСОБЕННОСТИ ЭКОНОМИКИ ЗНАНИЙ И ИХ ВЛИЯНИЕ НА ЭФФЕКТИВНОСТЬ РАЗВИТИЯ ИННОВАЦИОННО-ОРИЕНТИРОВАННЫХ ФИРМ
}

\author{
(c) 2021 Абдулганиев Ф.С. \\ доктор экономических наук, профессор \\ Казанский (Приволжский) федеральный университет, Россия, Казань \\ E-mail: Farid.Abdoulganiev@ksu.ru \\ (c) 2021 Маратканова Э. М. \\ старший преподаватель \\ Казанский инновационный университет, Россия, Казань \\ E-mail:mem1670@mail.ru
}

В статье уточнен состав элементов экономики знаний, рассматриваемый на микроуровне развития экономических систем, что позволяет повысить эффективность деятельности инновационноориентированных фирм за счет комплексного вовлечения в производственный процесс образовательного потенциала сотрудников, нематериальных активов, цифровых платформ и ресурсов образовательного и коммуникативного характера, активизации инвестиций в разработку и последующую коммерциализацию на рынке НИОКР объектов интеллектуальной собственности, совершенствования локального институционального обеспечения деятельности на основании системного учета внешних институтов экономики знаний. Дополнен состав институтов экономики знаний посредством включения в ее состав таких самостоятельных институтов, как институт цифровых платформ, институт ICO, институт е-learning (удаленного образования), институт социальных сетей в рамках пространства Интернет, институт проектного кредитования инновационных инициатив, институты краудсорсинга и инновационного франчайзинга. Дополненный состав институтов экономики знаний позволит рационализировать систему государственного регулирования данного сегмента постиндустриальной экономики в направлении повышения эффективности развития инновационно-ориентированных фирм различного масштаба и профиля деятельности. Показано, что инновационная инфраструктура оказывает существенное и разнонаправленное воздействие как на совершенствование механизмов современной экономики знаний, так и на функционирование значительной части инновационно-ориентированных фирм, в особенности кооперированных и интегрированных с объектами такого рода инфраструктуры. Охарактеризован элементный и субъектный состав современной инновационной инфраструктуры, показано их влияние на развитие институтов и механизмов экономики знаний.

Ключевые слова: экономика знаний, фирма, инновация, институциональные преобразования, инновационно-ориентированные фирмы, образовательный потенциал, нематериальные активы.

В обеспечении прогрессивного развития инновационно-ориентированных фирм различного масштаба и профиля деятельности в современных условиях хозяйствования значительное влияние оказывает такой ключевой элемент постиндустриальной экономики, как экономика знаний. На наличие тесной корреляции между процессами инновационного раз- вития фирм и функционированием экономики знаний указывают многие современные специалисты в области как экономической теории, так и практики управления хозяйственными системами, например Дж. Ходжсон", Р. Нельсон ${ }^{* *}$, Р.М.Нуреев ${ }^{\text {*t*a }}$, А.Н. Смирнова

Экономика знаний представляет собой систему отношений, организаций и инсти-

\footnotetext{
* Ходжсон, Дж. Экономическая теория и институты: Манифест современной институциональной экономической теории / Дж. Ходжсон // Пер. с англ. - М.: Дело, 2020. С.171.

** Nelson R. National Systems of Innovation: A Comparative Analysis. Oxford, 2013. P.32.

ж** Нуреев Р. М. Теория общественного выбора : курс лекций / Р. М. Нуреев. - М.: ГУ ВШЭ, 2005.

**** Смирнова А.Н. Особенности оценки эффективности инновационной деятельности предприятия. [Электронный ресурс]. Режим доступа: http://www.ibl.ru/konf/070411/22.html. Дата обращения: 5.06.2021.
} 
тутов, основанных на максимально полном использовании потенциала технологической и финансово-экономической информации в процессе развития систем макро-, мезо-, и микроуровня, трансформации знаний и компетенций персонала фирм, формируемых и развиваемых в процессе воспроизводства их человеческого капитала, как основной фактор повышения конкурентоспособности и обеспечения эффективности социально-экономического развития.

Несмотря на признание абсолютным большинством исследователей принципиального значения экономики знаний для развития современной экономики в целом и активизации деятельности инновационных компаний, в частности, в специальной литературе отсутствует единый подход к определению данного сегмента экономики, верификации ее структурных элементов.

По нашему мнению, в состав экономики знаний целесообразно включать следующие сегменты:

- финансирование сферы образования из всех источников (включая среднее общее и даже дошкольное образование, развитие которых формирует потенциал вероятных изменений экономики знаний в долгосрочной перспективе);

- объем цифровой экономики, кроме ее криминального и анти-этичного сегментов;

- емкость рынка объектов интеллектуальной собственности.

Тем самым, в отличие от некоторых подходов, предлагается включать в состав экономики знаний не только высшее и дополнительное образование, но и среднее общее (школьное), а также дошкольное образование - собственно, от качества последнего непосредственно зависит эффективность развития и механизмов экономики знаний, и инновационно-ориентированных фирм в долгосрочной перспективе.

Кроме того, при оценке масштабов экономики знаний предлагается исключать из объемов цифровой экономики, включаемой в ее состав, криминальный и анти-этичный сегменты. В состав первого входят цифровые ресурсы, связанные с распространением наркотических средств, оружия, порнографии, распространением интим-услуг, финансовых пирамид и иных, весьма распространенных в настоящее время схем интернет-мошенничества. К анти-этичным направлениям развития цифровых сервисов и платформ, которые также нецелесообраз- но включать в состав экономики знаний, входят написание фальшивых отзывов на компании и проекты в сетевом пространстве, аморальные по содержанию, хотя и формально законные, ютуб-каналы, инстаграмм-площадки, сайты легальных объектов игорного бизнеса (букмекерских компаний, лотерей) и т.п.

Достаточно проблематично точно оценить объем криминального сегмента цифровой экономики, который предлагается исключать при исследовании экономики знаний. Согласно укрупненной оценке Ф.Баннера, примерная доля данного сегмента в общей капитализации цифровой экономики составляла 25-30\%; соответственно, верхний предел такого рода оценки (с учетом емкости антиэтичного, хотя и формально легального сегмента) следует, на наш взгляд, использовать при рассмотрении того объема цифровой экономики, которая не входит в состав экономики знаний, никоим образом не способствует активизации процессов развития инновационно-ориентированных фирм.

Что же касается иных виртуальных цифровых процессов, цифровых сервисов и платформ, то даже выраженно коммерческие и финансовые сервисы такого рода в силу постоянного развития и совершенствования, типичного для любых сфер цифровизации, в любом случае способствуют активизации развития экономики знаний и, как следствие, росту обеспеченности информационными и иными аналогичными ресурсами субъектов хозяйствования различного профиля, в том числе, и инновационноориентированных фирм.

В соответствии с вышеизложенным можно укрупненно оценить емкость экономики знаний относительно динамики мирового валового продукта в целом (рисунок 1).

Как показано на рисунке 1, в 2012-2020 гг. доля экономики знаний в мировом ВВП возросла на 13,4 процентных пункта, что достаточно существенно. Основными факторами столь интенсивного роста являлись ускоренное развитие и совершенствование виртуального сегмента мировой цифровой экономики, а также прогрессивное развитие рынков НИОКР и интеллектуальной собственности, которое было опять-таки в значительной степени обусловлено интенсификацией процессов цифровизации инновационно-экономических взаимодействий. Кроме того, значительную роль в повышении доли экономики знаний в мировом ВВП сыграло качественное совершенствование систем уда- 


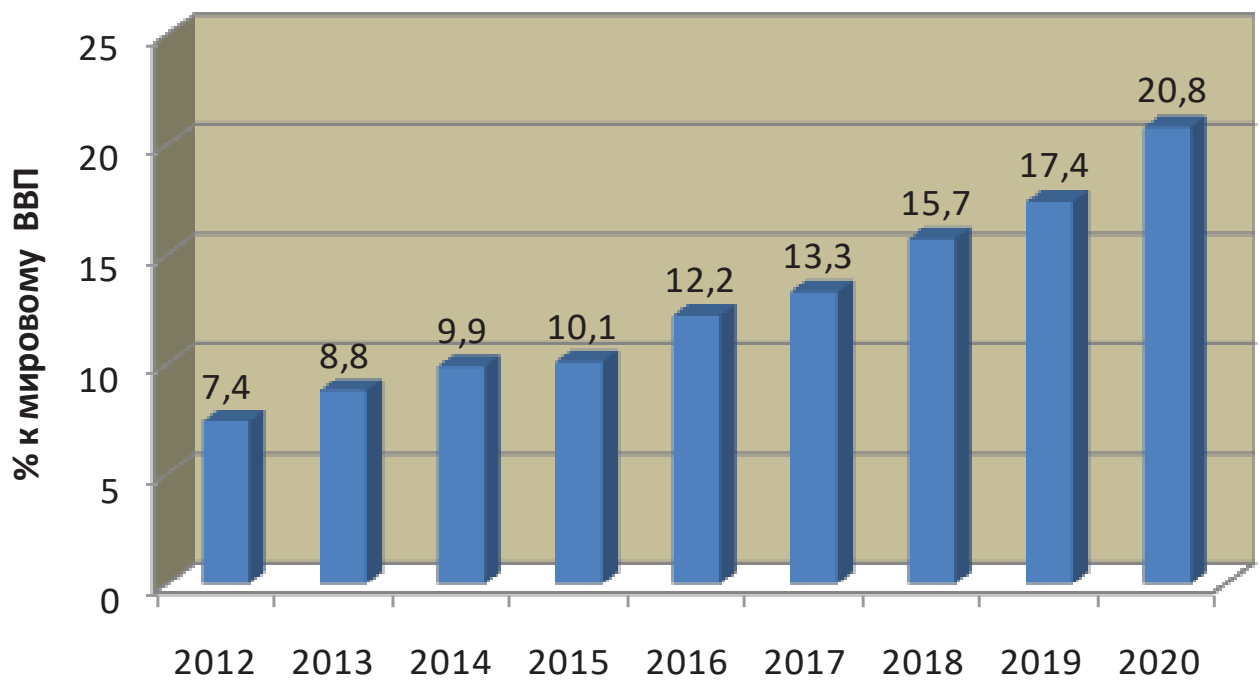

Puc. 1. Динамика емкости мировой экономики знаний относительно мирового ВВП,\% Рассчитано на основании информации, приведенной в: World Economy Statistics. Wash., 2021. P.171.

ленного образования, как индивидуального, так и корпоративного: согласно некоторым оценкам емкость мирового рынка e-learning, оказывающего непосредственное влияние как на эффективность экономики знаний, так и на развитие инновационно-ориентированных фирм в 2012-2020 гг., увеличилась в 3,75 раза".

Вместе с тем, в разрезе ведущих государств мировой экономики (РФ и страны блока G7, суммарно сформировавших в 2020 г. свыше 53,4\% мирового ВВП") доля экономики знаний относительно национального валового внутреннего продукта дифференцируется довольно значительно. Так, наименьший удельный вес экономики знаний относительно ВВП РФ по рассматриваемой группе государств, по нашему мнению, можно объяснить как сравнительно меньшими, по сравнению, например с США или Японией, темпами цифровизации экономических отношений, секвестированием государственного финансирования образовательных программ в 2010 гг., а также сравнительно неразвитым национальным рынков объектов интеллектуальной собственности - патентов, лицензий, ноу-хау и т.п.

Теоретически, как было отмечено ранее, развитие экономики знаний должно оказывать тесное и прямое влияние на уровень инновационной активности в рамках национальной финансово-экономической системы. Для проверки данного тезиса по группе рассматриваемых наиболее развитых рыночных государств мировой экономики воспользуемся инструментарием корреляционно-регрессионного анализа (рисунок 2).

Как показано на рисунке 2, по рассматриваемой группе государств в 2020 г. действительно имеет место статистически тесная, прямая и эластичная зависимость между долей экономики знаний и инновационной активностью в экономике государства по показателю доли инновационной продукции (работ, услуг) в структуре ВВП. Значение коэффициента детерминации, равное 0,945 , в наиболее общем виде свидетельствует о том, что на $94,5 \%$ в среднем по указанной группе стран динамика инновационной активности обуславливается факторами экономики знаний, прямым или опосредованным их воздействием.

Более того, экспоненциальный характер построенной функции свидетельствует о наличии прямого маржинального эффекта влияния роста экономики знаний на динамику инновационной активности в экономике: при прочих равных условиях увеличение капитализации экономики знаний на $1 \%$ ведет к увеличению доли инновационной продукции в структуре ВВП более, чем на $1 \%$, и по мере качественного совершенствования механизмов экономики знаний данная

\footnotetext{
* Российская экономика: проблемы и перспективы. - М.: Изд-во Института экономической политики, 2021. C.127.

** Россия и страны мира: статистический ежегодник. - М.: Из-во Федеральной службы государственной статистики, 2021.С.6.
} 


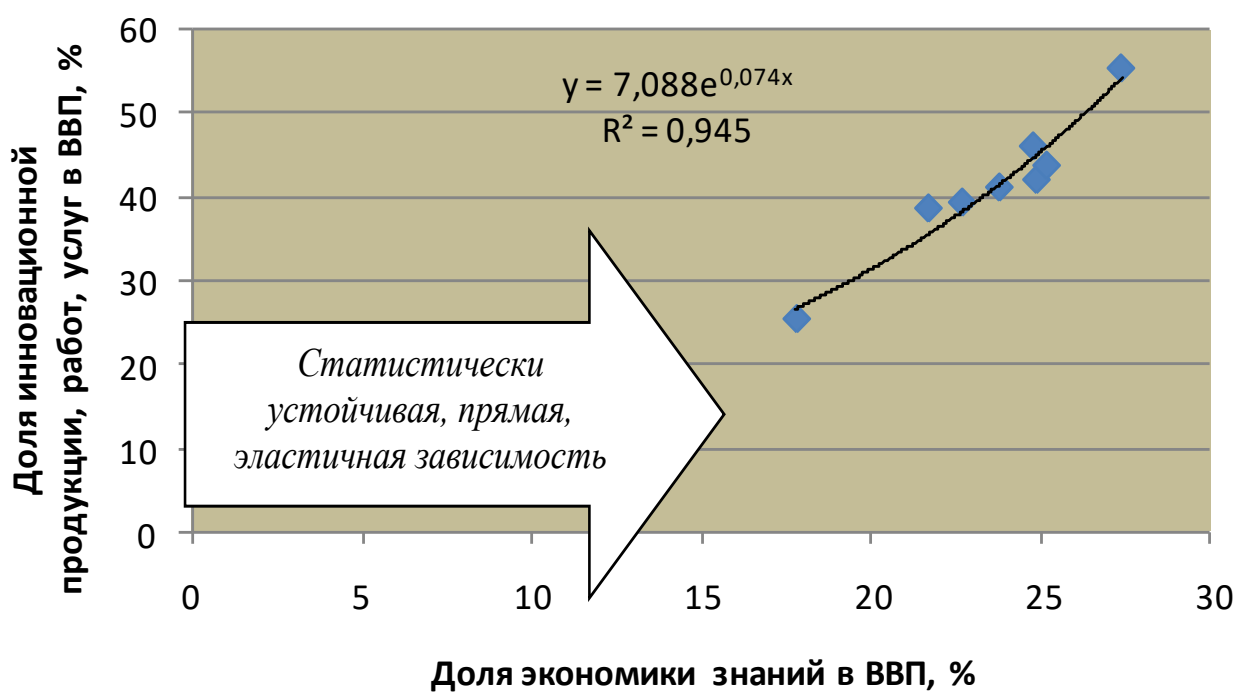

Puc. 2. Зависимость между долей экономики знаний в ВВП и удельным весом инновационной продукции (работ, услуг) в ВВП по группе государств G7 и РФ, 2020 г.

тенденция имеет тенденцию к усилению (маржинальный эффект выше в экономике Японии или Канады по сравнению с экономическими системами Италии или РФ, где интенсивность развития экономики знаний является сравнительно более низкой).

Таким образом, статистический анализ подтверждает эмпирический тезис относительно того, что прогрессивное развитие экономики знаний в условиях современной постиндустриальной, цифровой экономики является необходимым условием активизации инновационных процессов в национальной экономике в целом и сегменте инновационно-ориентированных фирм, в частности.

В соответствии с уточненным подходом к структуре экономики знаний автором диссертационного исследования дополнен состав элементов данного сегмента рыночной экономики. Они представлены на рисунке 3 нашего исследования.

Таким образом, в соответствии с предлагаемым подходом, элементами экономики знаний, оказывающими непосредственное влияние, в том числе, на эффективность развития инновационно-ориентированных фирм и совершенствования рассматриваемого сегмента экономических отношений на макроуровне, являются квалификационно-образовательный уровень персонала компаний, системы корпоративного образования, имеющиеся у фирм в собственности нематериальные активы различного уровня производительности, возможные инвестиции фирм в разработку и развитие объектов интеллектуальной собственности, цифровые образовательные и коммуникационные платформы, а также направления влияния институтов и институциональных изменений на использование такого рода базовых элементов экономики знаний.

В целом, приведенные на рисунке 3 дополненные автором элементы экономики знаний, рассматриваемые на микроуровне развития экономических систем, непосредственным образом взаимосвязаны. Так, внутрифирменные (корпоративные) образовательные программы при условии их рациональной организации обуславливают увеличение профессиональноквалификационного уровня персонала инновационно-ориентированных фирм и, как следствие, при наличии эффективной системы мотивирования креативного труда, их склонности к разработке и внедрению НИОКР. Использование современных, высокопроизводительных нематериальных активов, в первую очередь программного обеспечения и ERP-систем менеджмента фирм, позволяет экономить фонд рабочего времени специалистов фирмы на осуществление текущих трудовых операций и, соответственно, увеличивать объем временного фонда, который может быть потенциально использован на цели повышения качества инновационной деятельности. Инвестиции в разработку собственных объектов интеллектуальной собственности могут сформировать созданные самой компанией нематериальные активы, имеющие значение для внешних субъектов современной экономики знаний. 


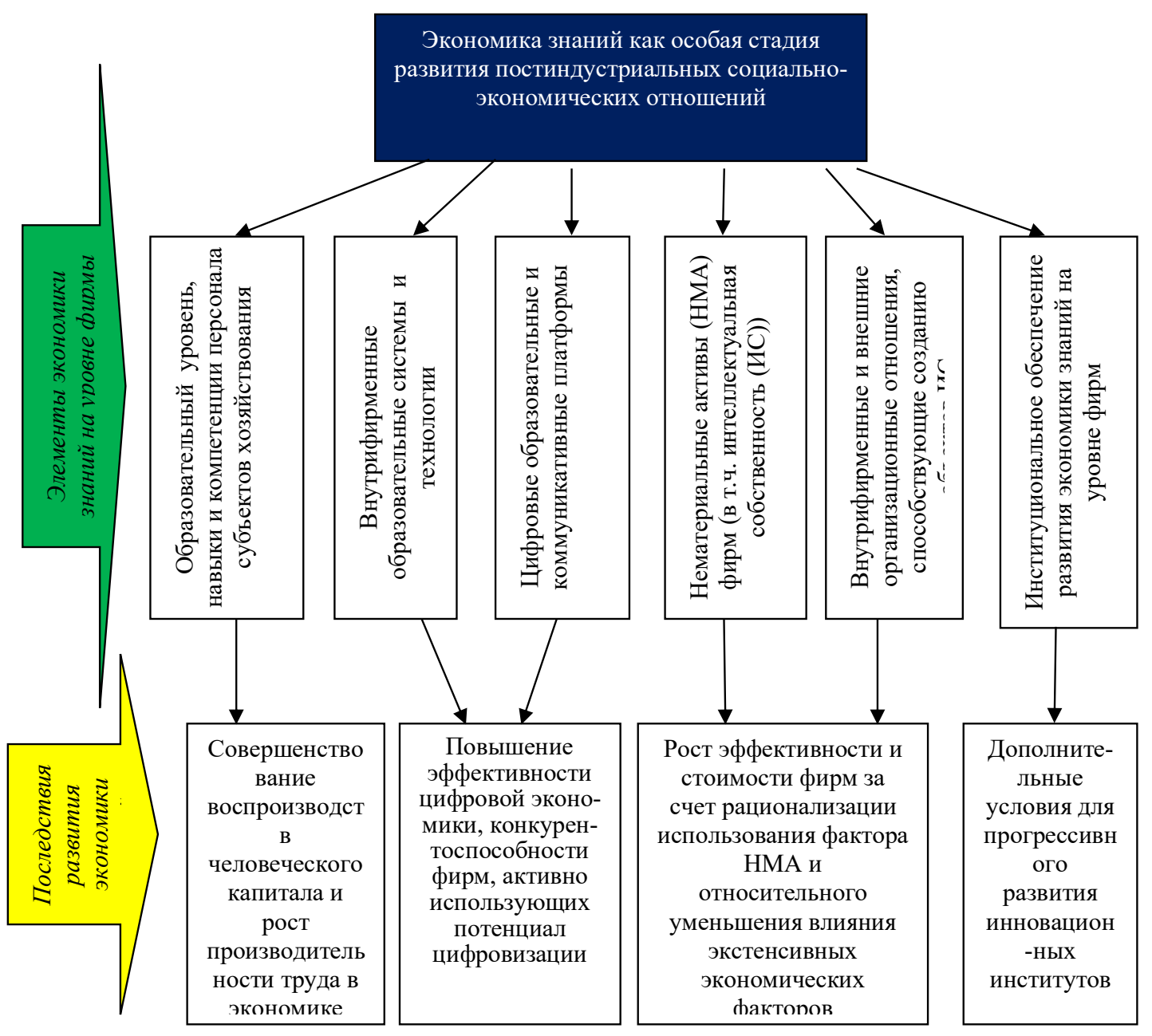

Puc. 3. Элементы экономики знаний на микроуровне и основные направления их влияния на развитие макроуровня данного сегмента постиндустриальной экономики (уточнено авторами)

На развитие современных инновационноориентированных фирм значительное влияние оказывает такой институт экономики знаний, как институт инновационной инфраструктуры. На основе анализа представленных в специальной литературе подходов нами уточнено и дополнено определение инфраструктуры, как особого экономического понятия. По нашему мнению, инфраструктуру целесообразно рассматривать в двух аспектах - широком и узком, а именно:

1. В широком смысле инфраструктура представляет собой систему социальноэкономических отношений физических или юридических лиц с экономическими субъектами сферы инноваций, информатизации, транспортных, логистических объектов и т.п. по вопросам, как правило, долгосрочного и относительно регулярного пользования услугами последних.
2. В узком смысле инфраструктура представляет собой комплекс материальновещественных объектов и непосредственно связанных с ними экономических субъектов, осуществляющих на условно-бесплатной или возмездной основе работы и оказывающих квалифицированные услуги частным лицам и компаниям, ориентированные на повышение качества жизни домохозяйств или увеличение эффективности воспроизводственного процесса субъектов хозяйствования.

Отличительными особенностями уточненного и дополненного нами определения инфраструктуры, как особого понятия экономической теории, соответственно, являются:

a) рассмотрение инфраструктуры в широком смысле, как системы особых социальноэкономических отношений, является новым для экономической науки и, по нашему мнению, не- 
сколько более корректным и продуктивным, нежели достаточно широко представленное в современной экономической теории понимание инфраструктуры, как специального экономического института.

б) в отличие от достаточно широко представленных в специальной литературе подходов, предлагается при рассмотрении инфраструктуры в узком смысле рассматривать последнюю не только как систему некоторых материальновещественных объектов (дорог, складов, технопарков, бизнес-инкубаторов и т.п.), но и субъектов, непосредственно ответственных за развитие такого рода неодушевленных объектов инфраструктурного характера. Подобный подход позволяет более широко рассмотреть спектр возможных взаимодействий пользователей с элементами различных видов инфраструктуры, включая возможные конфликтные или компромиссные вариации такого рода взаимодействия.

в) предлагается, в отличие от некоторых определений, рассматривать пользование элементами экономической инфраструктуры, как всегда возмездное, хотя и в некоторых случаях носящее условно-бесплатный характер.

г) в рамках уточненного и дополненного нами определения акцентируется взаимос- вязь между особенностями функционирования и развития инфраструктуры и не только эффективностью воспроизводства деятельности субъектов хозяйствования, но и качеством жизни населения. Вместе с тем, на повышение качества жизни различных групп населения оказывает существенное влияние не только транспортная инфраструктура или инфраструктура рынка труда, что очевидно, но и инфраструктура товарной и фондовой биржи, логистических объектов, инновационной сферы экономики.

Эффективность развития современной инновационной инфраструктуры любого уровня социально-экономической системы (федерального, регионального, муниципального) непосредственно зависит от рациональности формирования и последующего совершенствования структурных компонентов такого рода инфраструктуры, степени их согласованности друг с другом, уровня положительной синергии взаимодействия. Дифференциация основных видов элементов инновационной инфраструктуры, оказывающих то или иное влияние на развитие инновационно-ориентированных фирм в парадигме современной экономики знаний, представлена в таблице 1.

Таблица 1. Основные элементы инновационной инфраструктуры экономики знаний и виды субъектов, интегрированных с нею

\begin{tabular}{|c|c|}
\hline $\begin{array}{l}\text { Элементы и эконо- } \\
\text { мические субъекты }\end{array}$ & Наименование \\
\hline $\begin{array}{l}\text { 1. Материально- } \\
\text { вещественные } \\
\text { элементы }\end{array}$ & $\begin{array}{l}\text { технопарки; технополисы; бизнес-инкубаторы; особые экономические зоны (ОЭ3) } \\
\text { при условии, что инновационное развитие является их ключевым приоритетом; } \\
\text { транспортно-логистические объекты в рамках инновационной инфраструктуры; адми- } \\
\text { нистративные объекты инновационной инфраструктуры. }\end{array}$ \\
\hline $\begin{array}{l}\text { 2. Субъектный } \\
\text { состав } \\
\text { инновационной } \\
\text { инфраструктуры }\end{array}$ & $\begin{array}{l}\text { резиденты инновационной инфраструктуры, как правило инициаторы стартапов; } \\
\text { корпус менеджеров и специалистов проектов и программ, реализуемых в рамках } \\
\text { инновационной инфраструктуры; административный состав инновационной инфра- } \\
\text { структуры; «бизнес-ангелы»- стратегические инвесторы в стартап, непосредственно } \\
\text { аффилированные с инновационной инфраструктурой; корпоративные университеты } \\
\text { в рамках инновационной инфраструктуры; организации СПО и НПО в пространстве } \\
\text { инновационной инфраструктуры. }\end{array}$ \\
\hline $\begin{array}{l}\text { 3. Экономические } \\
\text { субъекты, } \\
\text { кооперированные } \\
\text { интегрированные } \\
\text { с инновационной } \\
\text { инфраструктурой }\end{array}$ & $\begin{array}{l}\text { профильные органы государственного регулирования и программирования развития } \\
\text { инновационной инфраструктуры; организации ВО и СПО, кооперированные с инно- } \\
\text { вационной инфраструктурой; внешние субъекты хозяйствования (корпорации, уч- } \\
\text { реждения, НИИ), кооперированные и интегрированные с объектами инновационной } \\
\text { инфраструктуры на длительной основе; кредитные организации, регулярно осущест- } \\
\text { вляющие кредитование развития самой инновационной инфраструктуры и проектов, } \\
\text { осуществляемых в ее рамках; страховые организации, кооперированные с инновацион- } \\
\text { ной инфраструктурой; внешние стратегические инвесторы в инновационные проекты } \\
\text { и стартапы; консультанты и информационные посредники, оказывающие услуги для } \\
\text { инновационной инфраструктуры и проектов, осуществляемых на ее основе }\end{array}$ \\
\hline
\end{tabular}

Источник: Хомутский, Д. Ю. Управленческая оценка и отбор инновационных проектов // Менеджмент инноваций. - 2009. № 2 - С. 110. 
Субъектами корпоративной интеграции с инновационной инфраструктурой и ее объектами и проектами могут выступать различного рода организации, как правило, относящиеся к коммерческому сектору экономики, сфере инвестиционных фондов или государственному управления, которые приобретают акции, доли, облигации или токены как самой инфраструктуры, как особого юридического лица, так и инновационных проектов или стартапов, формируемых и осуществляемых в ее рамках, на базе инфраструктурного производственнотехнологического потенциала. В соответствии с нормами действующего в РФ законодательства об акционерных обществах и обществах с огра- ниченной ответственностью, субъекты корпоративной интеграции, соответственно, могут, хотя и не обязаны, осуществлять самоуправление развитием инновационной инфраструктуры или реализуемых в ее пространстве инвестиционных проектов.

Таким образом, в целом, инновационная инфраструктура оказывает существенное и разнонаправленное воздействие как на совершенствование механизмов современной экономики знаний, так и на функционирование значительной части инновационно-ориентированных фирм, в особенности кооперированных и интегрированных с объектами такого рода инфраструктуры.

\section{Библиографический список}

1. Бурденко Е.В. Рейтинги и индексы, оценивающие развитие экономики знаний // Креативная экономика. 2019. - № 5. - C. 54.

2. Иншаков М. О. Инновационные стартапы в России: проблемы создания и маркетингового продвижения/ М. О.Иншаков // Вестник Волгоградского государственного университета, 2017. № 1.

3. Коростышевская Е.М., Миэринь Л. А., Фахрутдинова Е. В. Инновационная система ЕС и место России в европейском инновационном пространстве// Современное искусство экономики. 2015. № 2(20). С. 59-67.

4. Морковина С.С. Инновационные механизмы взаимодействия стартапов и инвесторов в интернетпространстве / С. С. Морковина // Социально-экономические явления и процессы, 2020. № 5.

5. Нуреев Р. М. Теория общественного выбора: курс лекций / Р. М. Нуреев. - М.: ГУ ВШЭ, 2005.

6. Российская экономика: проблемы и перспективы. - М.: Изд-во Института экономической политики, 2021. -323 c.

7. Россия и страны мира: статистический ежегодник. - М.: Из-во Федеральной службы государственной статистики, 2021. -582 с.

8. Смирнова А.Н. Особенности оценки эффективности инновационной деятельности предприятия. [Электронный ресурс]. Режим доступа: http://www.ibl.ru/konf/070411/22.html. Дата обращения: 5.06.2021.

9. Фахрутдинова Е.В. Качество жизни населения в системе социально-экономических отношений (институциональный подход) // диссертация на соискание ученой степени доктора экономических наук / Казанский финансово-экономических институт. Казань, 2010. - 420с.

10. Фахрутдинова Е.В. Человеческий капитал в Республике Татарстан: динамика развития// Вопросы экономики и права. 2013. № 66. С. 121-124.

11. Хафизов Н.А. Проблемы и перспективы развития экономической инфраструктуры // Вестник экономики и управления. 2021. № 5.

12. Ходжсон Дж. Экономическая теория и институты: Манифест современной институциональной экономической теории / Дж. Ходжсон // Пер. с англ. - М.: Дело, 2020.

13. Хомутский Д. Ю. Управленческая оценка и отбор инновационных проектов // Менеджмент инноваций. 2009. - № 2 - C. 110 .

14. Banner F. Crowdsourcing the law. - Wash., 2019.

15. Kay N.M. The innovating firm / N. M. Kay. - London, 2019.

16. McCelvey $J$. The innovation stack. NY.: Penguin, 2020.

17. Nelson R. National Systems of Innovation: A Comparative Analysis. Oxford, 2013.

18. Sebastian J. The finishing stroke of infrastructure. NY.: ABC-press, 2020.

19. World Economy Statistics. Wash., 2021. 